\title{
Demonstration of the Retrograde Transport of Nerve Growth Factor Receptor in the Peripheral and Central Nervous System
}

\author{
Eugene M. Johnson, Jr., ${ }^{1}$ Megumi Taniuchi, ${ }^{1}$ H. Brent Clark, ${ }^{2, a}$ Joe E. Springer, ${ }^{3}$ Sookyong Koh, ${ }^{3}$ Mark W. \\ Tayrien, ${ }^{3}$ and Rebekah Loy ${ }^{3}$ \\ Departments of ${ }^{1}$ Pharmacology and ${ }^{2}$ Pathology, Washington University Medical School, St. Louis, Missouri 63110, and \\ ${ }^{3}$ Department of Neurobiology and Anatomy, University of Rochester School of Medicine, Rochester, New York 14642
}

\begin{abstract}
NGF acts on responsive neurons by binding to specific NGF receptors on axonal termini, after which a critical biochem. ical signal is retrogradely transported to the cell body. The identity of the signal(s) is unknown; candidates include NGF itself or some other "second messenger." A possible second messenger is the NGF receptor. As a first step in assessing the possible role of NGF receptor in the generation of the NGF-dependent signal, and in understanding the economy of NGF receptor synthesis and utilization, we determined whether the NGF receptor is retrogradely transported. Using immunohistochemical staining with a monoclonal antibody (192-IgG) against rat NGF receptor, we looked for accumulation of NGF receptor molecules distal (retrograde transport), as well as proximal (anterograde transport), to sites of axonal ligation or transection. By 10$12 \mathrm{hr}$ in both the ligated sciatic nerve and the lesioned fimbria-fornix, accumulated NGF receptor was detected proximal and distal to the ligation/lesion site. The transported receptor presumably was located in sympathetic and sensory neurons in the sciatic nerve and in forebrain cholinergic neurons projecting from the medial septum to the hippocampus. In both anatomical sites, accumulation of NGF receptor on the proximal (anterograde) side occurred in streams of fine axonal processes, whereas staining on the distal (retrograde) side occurred in varicose or granular configurations. These results raise the possibility that the NGF receptor has a role in the mechanism of NGF beyond the initial binding event at the plasma membrane of the axonal terminus.
\end{abstract}

Developing and, to a lesser cxtent, mature neurons require contact with target tissues for survival or maintenance of normal function. The trophic support provided by target tissues generally is ascribed to the elaboration of neurotrophic factors upon which the innervating neuron is dependent. To date, the only neurotrophic factor of demonstrated physiological significance is NGF, which is required by sympathetic and neural crest-

\footnotetext{
Received Aug. 5, 1986; revised Oct. 3, 1986; accepted Oct. 17, 1986.

This work was supported by NSF Grant NS8511564, by the Washington University Alzheimer's Disease Research Center (NIH Grant AG05681), and by a grant from the Monsanto Co., St. Louis.

Correspondence should be addressed to Eugene M. Johnson, Jr., Department

of Pharmacology, Box 8103, Washington University School of Medicine, 660

South Euclid Avenue, St. Louis, MO 63110.

a Present address: Department of Laboratory Medicine, Memorial Medical Center, Springfield, IL 62708 .

Copyright (C) 1987 Society for Neuroscience $0270-6474 / 87 / 030923-07 \$ 02.00 / 0$
}

derived sensory neurons (for reviews, see Levi-Montalcini and Angeletti, 1968; Thoenen and Barde, 1980; Johnson et al., 1986). Therefore, NGF is regarded as the prototype of a group of factors involved in mediating target support of neurons. NGF is thought to act by a series of steps involving synthesis and release of NGF by target tissues of sympathetic and sensory neurons, the binding of the NGF to specific NGF receptors on terminal portions of axons, the internalization of the NGF, and the subsequent retrograde transport of NGF to the cell body. The biochemical mechanism by which NGF sustains the viability and/or maintains the morphological and biochemical properties of the neuron is not known.

There is considerable evidence for each step in this scheme. Both mRNA encoding NGF and NGF itself are produced in target tissues and are present in quantities generally correlating with density of innervation (Ebendal et al., 1983; Korsching and Thoenen, 1983a; Shelton and Reichardt, 1984). Exogenously administered ${ }^{125}$ I-NGF is retrogradely transported in a specific, saturable manner by sympathetic and sensory neurons (Hendry et al., 1974; Stöckel et al., 1975). The retrograde transport of endogenous NGF has been demonstrated by immunoassay (Korsching and Thoenen, 1983b) and by immunohistochemical methods (Palmatier et al., 1984). Interruption of retrograde axonal transport by chemical means produces adverse effects in neurons similar to those produced by axotomy or by NGF deprivation induced by antibodies to NGF (Purves, 1976).

One uncertainty in the scheme is the nature of the molecular signal that reaches the cell body and produces the trophic effects associated with exposure of the terminal part of axons to NGF. It is clear that NGF is retrogradely transported from the target to the cell body and that a retrogradely transported message dependent on, or generated by, the interaction of NGF with the axonal plasmalemma is required by sensitive neurons. It is not clear, however, that the NGF molecule itself is the retrogradely transported message. Some other "second messenger" generated by the NGF:NGF receptor interaction could be the signal to which the cell body actually responds. Potential "second messengers" include the NGF receptor, the NGF:NGF receptor complex, or receptor modified by the interaction with NGF at the terminal. Such mechanisms would necessarily depend on retrograde transport of the receptor. It also is possible that the receptor mediates only the binding and perhaps the internalization of NGF, with NGF dissociating from the receptor prior to transport. If this were the case, NGF, but not its receptor, would be transported to the cell soma.

As a first step in assessing the possible role of NGF receptor 


\section{A}

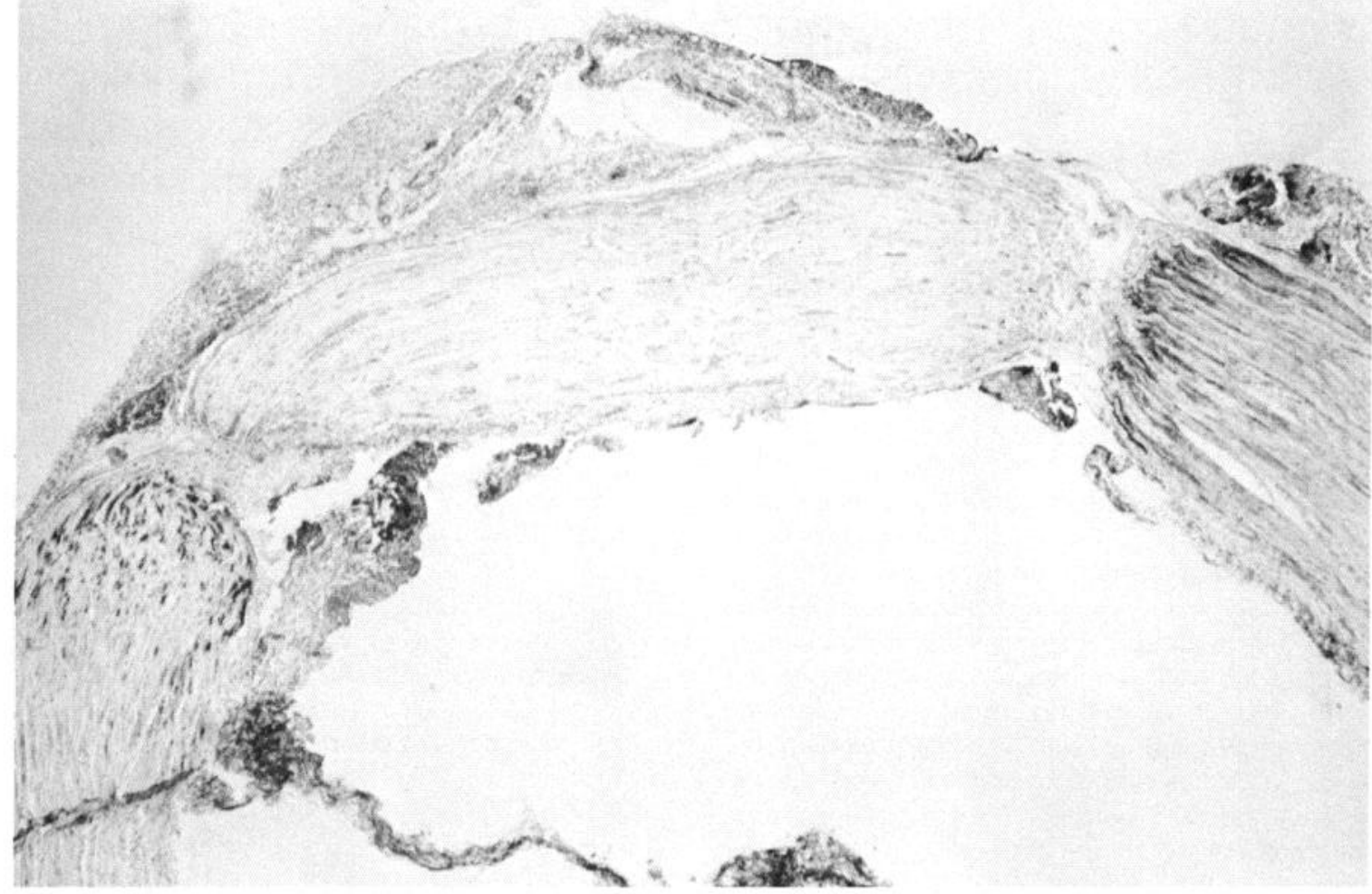

\section{B}

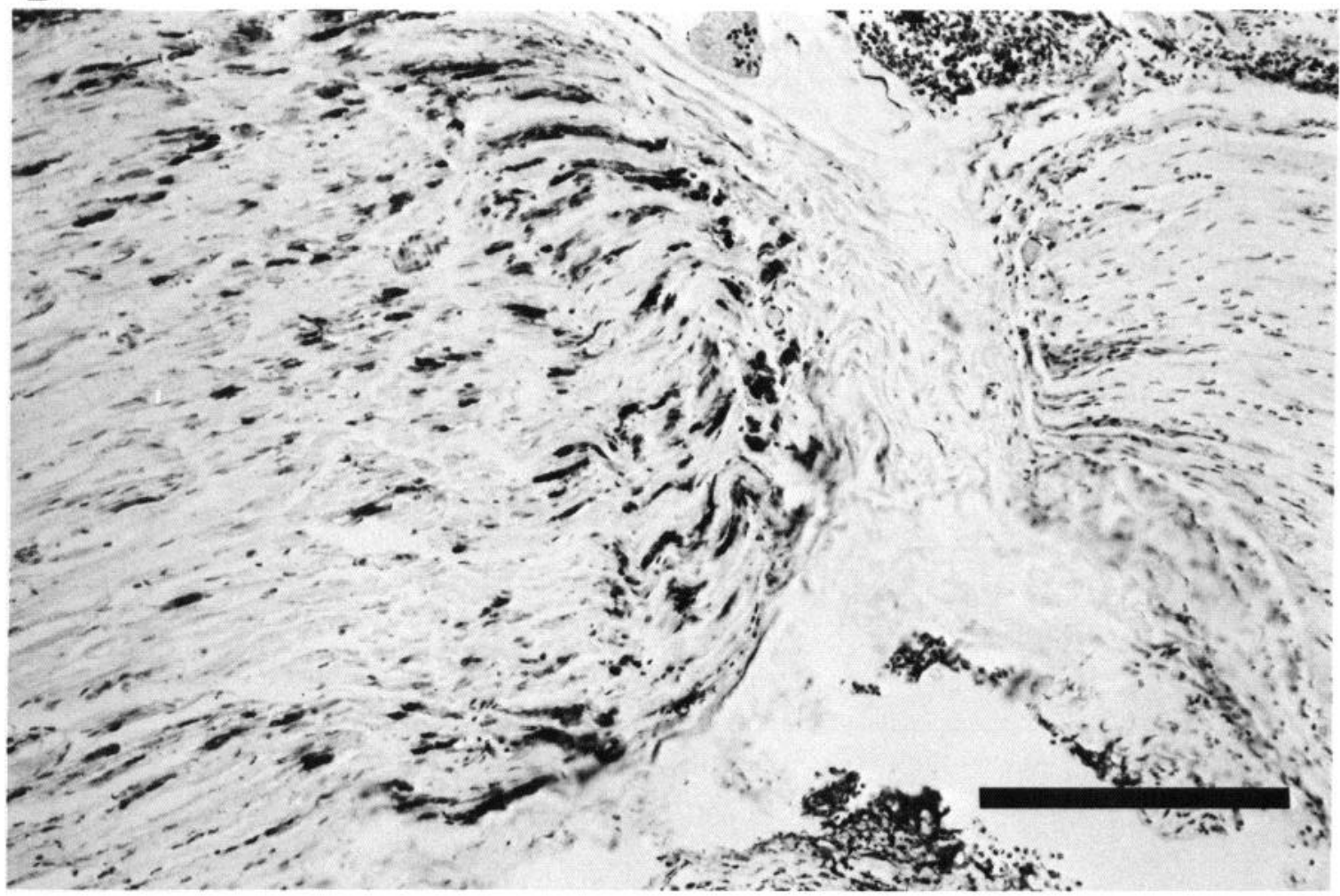




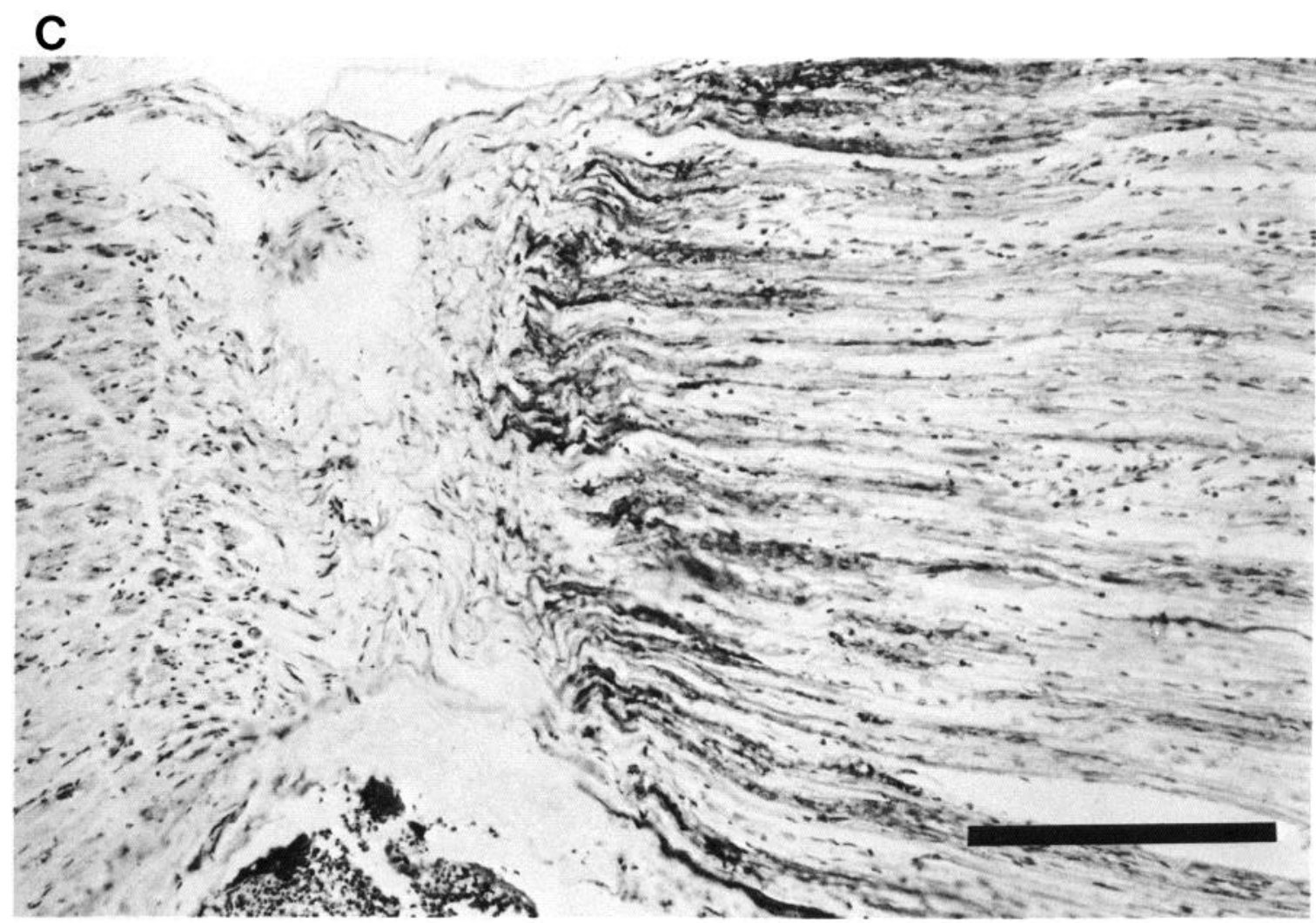

Figure 1. Photomicrography showing accumulation of antero- and retrogradely transported NGF receptor. $A$, Adult rat sciatic nerve was doubly ligated ( $3 \mathrm{~mm}$ apart) for $14 \mathrm{hr}$ and processed by immunohistochemistry with 192-IgG, as described in Materials and Methods, and counterstained with hematoxylin. The proximal ligation is on the right. $B$, Higher-power view (bar, $100 \mu \mathrm{m}$ ) of distal ligation shown in $A$. $C$, Higher-power view (bar, $100 \mu \mathrm{m}$ ) of proximal ligation shown in $A$.

in the generation of the NGF-dependent signal and in understanding the economy of NGF receptor synthesis and utilization, it is necessary to determine whether the NGF receptor, in fact, is retrogradely transported. The recent development and characterization of a monoclonal antibody directed against rat NGF receptor molecules permits a direct approach to this question. The monoclonal antibody (192-IgG) was generated by immunization of mice with solubilized PC12 cell membranes (Chandler et al., 1984). This monoclonal antibody does not inhibit NGF binding, but rather increases the affinity of NGF for NGF receptors. Radiolabeled $192-\mathrm{IgG}$ is retrogradely transported in rat sympathetic and sensory neurons (Taniuchi and Johnson, 1985). 192-IgG can be used to immunoprecipitate NGF receptors and, as an immunohistochemical tool, to localize NGF receptors anatomically, independent of the occupation of the receptor by NGF (Taniuchi et al., 1986a, b).

In addition to the demonstrated physiological role of NGF in sympathetic and neural crest-derived sensory neurons, evidence has recently accumulated suggesting a similar role for NGF in promoting cellular functions in neurons of the CNS, particularly those of the central forebrain cholinergic system (Gnahn et al., 1983; Hefti et al., 1984; Seiler and Schwab, 1984; Korsching et al., 1985). We have recently shown that $192-\mathrm{IgG}$ immunoprecipitates NGF receptor molecules from brain that appear identical to those in sympathetic neurons. We also have shown that ${ }^{125} \mathrm{I}-192-\mathrm{IgG}$ is retrogradely transported, as is ${ }^{125} \mathrm{I}-$ NGF, from target areas of the central forebrain cholinergic system (cortex, hippocampus) to large neurons in the nucleus basalis, medial septal nucleus, and diagonal band of Broca (Taniuchi et al., 1986a). Thus, $192-\mathrm{IgG}$ can be used as a probe for NGF receptor molecules in both the PNS and CNS.

If the NGF receptor is retrogradely transported, either constitutively or in response to NGF occupation, NGF receptor molecules should accumulate on the distal side of a ligation of NGF transporting axons in a manner similar to that seen for NGF. In contrast to NGF, the NGF receptor would, of course, be transported in both directions because NGF receptor in terminal areas must be synthesized in the perikaryon and transported anterogradely. We have tested this hypothesis by ligating or lesioning axons of NGF-responsive neurons in the periphery (sciatic nerve) and in the CNS (fimbria-fornix). In this paper we demonstrate immunohistochemically that the NGF receptor is retrogradely and anterogradely transported in these axons.

\section{Materials and Methods}

Monoclonal antibody $192-\operatorname{IgG}$ was purified from mouse ascites by the Bio-Rad Monoclonal Antibody Purification System. Monoclonal antibody 151 , which served as a negative control $\mathrm{IgG}$, is directed against the rat epidermal growth factor (EGF) receptor (Chandler et al., 1985) and was purified from tissue culture supernatants on a Pharmacia protein A-Sepharose column.

For experiments on peripheral nerve, adult male Sprague-Dawley rats were anesthetized with chloral hydrate $(350 \mathrm{mg} / \mathrm{kg}$, i.p.) and the sciatic nerve was exposed. Ligatures (6-0 silk) were placed at the site where the nerve passed dorsal to the tendon of the obturator internus muscle. For double ligation experiments, 2 ligatures were placed approximately $3 \mathrm{~mm}$ apart. After 7 or $14 \mathrm{hr}$, the rats were decapitated and a $1.5 \mathrm{~cm}$ section of sciatic nerve surrounding the ligation site was removed and 

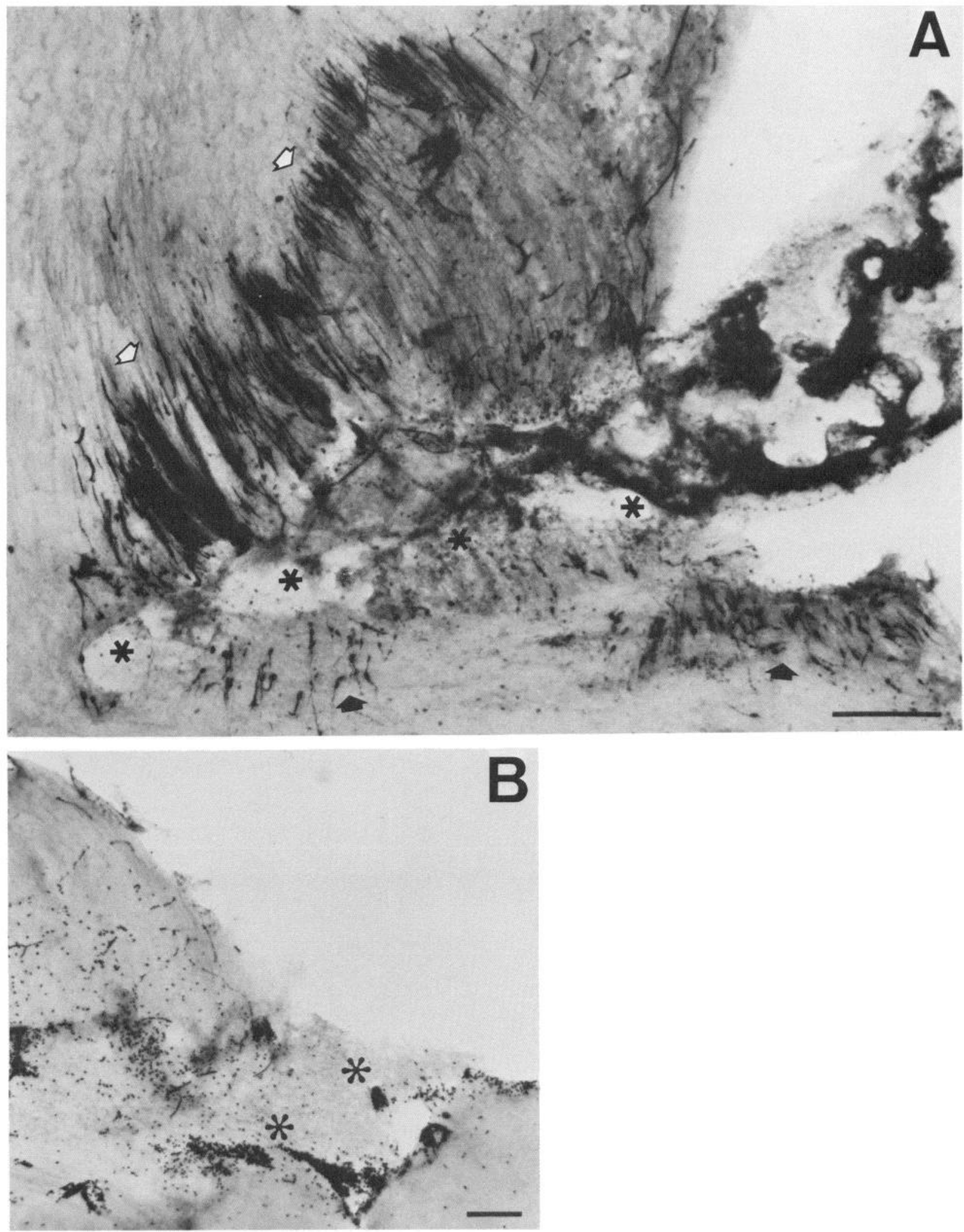

Figure 2. A, Photomicrograph of a horizontal section through the septum and fimbria stained with 192-IgG. Anterograde (open arrows) and retrograde (closed arrows) accumulation of NGF-receptor immunoreactive fibers shown in the septum (proximal) and fimbria (distal) $12 \mathrm{hr}$ following fimbria-fornix transection (asterisks). Scale bar, $100 \mu \mathrm{m}$. B. Photomicrograph of a section adjacent to the one in $(A)$, showing lack of immunoreactive fiber staining using negative control antibody $151-\mathrm{IgG}$. Scale bar, $100 \mu \mathrm{m}$. 
fixed overnight by immersion in $4 \%$ paraformaldehyde $/ 100 \mathrm{mM} \mathrm{NaP}_{\mathrm{i}}$, $\mathrm{pH} 7.4$, and frozen in liquid nitrogen.

Frozen fixed sciatic nerves were sectioned in a cryostat and placed on glass microscopic slides. The sections were exposed to $5 \mu \mathrm{g} / \mathrm{ml} \mathrm{192-}$ IgG or negative control antibody (151-IgG) in a buffer composed of 10 $\mathrm{mm} \mathrm{K} \mathrm{HPO}_{4}, 160 \mathrm{~mm} \mathrm{NaCl}, 5 \%$ heat-inactivated horse serum, and $0.02 \% \mathrm{NaN}_{3}$. After overnight binding at $4^{\circ} \mathrm{C}$ the sections were washed with PBS and incubated for $3 \mathrm{hr}$ at $22^{\circ} \mathrm{C}$ with $1 \mu \mathrm{g} / \mathrm{ml}$ biotinylated horse anti-mouse IgG immunoglobulins. The sections then were washed and incubated for $2.5 \mathrm{hr}$ at $22^{\circ} \mathrm{C}$ with a complex of avidin and biotinylated HRP (Vectastain). After several washes the sections were reacted for 5 $\min$ in $0.05 \% 3,3^{\prime}$-diaminobenzidine and $0.01 \%$ hydrogen peroxide, counterstained with hematoxylin, and mounted with coverslips.

Experiments involving CNS lesions were carried out on 9 adult female Sprague-Dawley rats (200-250 g) anesthetized with sodium pentobarbital $(40 \mathrm{mg} / \mathrm{kg})$. Unilateral transections of the fimbria-fornix were made using a stereotaxically guided 3-mm-wide microknife inserted $5 \mathrm{~mm}$ ventral from the dura $1 \mathrm{~mm}$ postcrior to brcgma. Twclve hours following surgery, the rats were again anesthetized and perfused transcardially with PBS, followed by $4 \%$ paraformaldehyde in $0.2 \mathrm{~m}$ sodium acetate, $\mathrm{pH} 6.5$, and then $4 \%$ paraformaldehyde in $0.1 \mathrm{~m}$ phosphate buffer, $\mathrm{pH}$ 8.5. Horizontal, $50 \mu \mathrm{m}$ Vibratome sections were collected and processed for immunohistochemistry, as described above.

\section{Results}

\section{Transport of NGF receptor in the periphery}

The retrograde axonal transport of endogenous NGF has been demonstrated in superior cervical postganglionic nerve (Palmatier et al., 1984) and sciatic nerve (Korsching and Thoenen, 1983 b) by ligating the nerve and detecting accumulation of NGF on the distal side of the ligation. Using the same paradigms, we have applied 192-IgG as an immunohistochemical probe for the NGF receptor to determine if bidirectional transport of receptor molecules occurred. Sciatic nerves ligated for $14 \mathrm{hr}$ and processed for immunohistochemistry as described in Materials and Methods showed intense staining with 192-IgG on both sides of a single ligation (not shown). The presence of immunoreactive material distal and proximal to the ligature indicated that NGF receptor molecules had been in transit in both retrograde and orthograde directions, respectively, during the period of ligation. Immunostaining was clear but less intense after 7 hr of ligation.

To show the accumulation of anterogradely and retrogradely transported receptors more clearly and to exclude possible artifacts due to nerve trauma associated with ligation, a second protocol that provided better internal control was performed. Two ligatures were placed $3 \mathrm{~mm}$ apart on a sciatic nerve, and the 192-IgG immunoreactive material accumulating on both sides of each tie was observed $14 \mathrm{hr}$ after double ligation (Fig. $1 A)$. The immunoreactive material accumulated peripheral to the distal lesion and central to the proximal lesion, but very little was detected in the portion of the nerves between the ligatures. The prominent staining obtained distal and proximal to the middle region indicated, as before, the accumulation of NGF receptors that were transported retrogradely and anterogradely. Within the $3 \mathrm{~mm}$ segment, the faint staining was localized adjacent to the ligations and presumably represented the small amounts of receptor in transit and trapped in the $3 \mathrm{~mm}$ segments. The alternation in staining distribution observed after double ligation precludes the possibility that the accumulation of immunoreactive materials is an artifact of local tissue damage caused by ligation itself. In addition, sections of single or doubleligated sciatic nerves showed no staining with a negative control monoclonal antibody (151-IgG; not shown).

Immunoreactive material extended $\sim 1 \mathrm{~mm}$ from each ligature, with a more extended region of staining on the proximal side. The patterns of staining proximally and distally were qualitatively different. The staining on the distal side (Fig. $1 B$ ) was concentrated in granular or short fusiform configurations, whereas on the proximal side (Fig. $1 C$ ) the staining was distributed in longer attenuated figures, as in a stream. These differences were seen at both single (not shown) and double ligations (Fig. 1, B, C).

\section{Transport of NGF receptor in CNS}

Intrahippocampally injected ${ }^{125}$ I-NGF (Seiler and Schwab, 1984) or ${ }^{125} \mathrm{I}-192-\mathrm{IgG}$ (Taniuchi et al., 1986a) is retrogradely transported in a specific manner to the medial septal and diagonal band nuclei. In the present experiments, cell bodies immunoreactive for NGF receptor were located in the medial septal nucleus and the vertical limb of the diagonal band (not shown). Since the major route by which septal axons enter the hippocampus is the fimbria-fornix, the fimbria-fornix was transected unilaterally at the level where it joins the septum (see asterisks in Fig. $2 A$ ). Possible accumulation of NGF receptors at the lesion site was assessed by 192-IgG immunohistochemistry.

Twelve hours after the transection of the fimbria-fornix both the distal and proximal cut axons showed intense immunoreactivity (Fig. $2 A$ ) when stained with $192-\mathrm{IgG}$. This indicates that endogenous NGF receptors are transported retrogradely and anterogradely in this tract. By $20 \mathrm{hr}$ after transection, accumulated immunoreactive material was apparent only on the proximal side of the lesion, and by $48 \mathrm{hr}$, no intense immunoreactivity occurred either proximally or distally (not shown).

As after short periods of ligation of the sciatic nerve (Fig. 1), the pattern of immunoreactivity at $12 \mathrm{hr}$ following fimbrial transection differcd in axons distal and proximal to the cut. The former was relatively short and varicose, while the latter was more numerous, smooth, and stained for longer distances, extending into the medical septum (open arrows in Fig. $2 A$ ). No immunoreactivity occurred at the transection site when a negative control IgG antibody, 151-IgG (Fig. 2B), was substituted for 192-IgG or when primary antibody was omitted.

\section{Discussion}

The results reported here demonstrate that the NGF receptor is transported both anterogradely and retrogradely in the sciatic nerve and in the fornix-fimbria. This transport of receptor presumably occurs in sympathetic and sensory neurons in the sciatic nerve and in forebrain cholinergic neurons projecting from the medial septum to the hippocampus. The conclusion that the NGF receptor is retrogradely transported is based upon the pattern of immunohistochemical staining with $192-\mathrm{IgG}$ of axons that were interrupted for several hours, which permitted the accumulation of transported receptor at the ligation/lesion site. The pattern of staining is consistent with that of immunohistochemical localization of a molecule undergoing antero- and retrograde transport, i.e., accumulation within the first few millimeters on both sides of the site of interruption. Little or no specific staining could be visualized in the absence of lesion. No specific staining was observed at the lesion site when negative control antibody (151-IgG) or no primary antibody was substituted for 192-IgG.

Further evidence for the transport of receptor was shown in sciatic nerve where multiple ligations are possible. Thus, when 2 ties were placed a few millimeters apart, reaction product was seen in large quantities central to the proximal tie and peripheral to the distal tie. As expected of a transported protein, only a 
small amount of reaction product was seen distal to the proximal tie and proximal to the distal tie (i.e., within the isolated segment), providing further evidence that $192-\mathrm{IgG}$ was not binding nonspecifically at a nerve compression site. In both the sciatic nerve and fimbria, accumulation of NGF receptor on the proximal (anterograde) side occurred in streams of fine axonal processes, whereas staining on the distal (retrograde) side occurred in varicose or granular configurations. These differences may reflect different molecular mechanisms of the retrograde and anterograde transport of receptor or the fact that the distal segments are undergoing more rapid degeneration. Studies of the accumulated receptor by EM immunocytochemistry using 192 IgG, currently in progress, may provide some insight into this issue.

The demonstration of the retrograde transport of the NGF receptor provided by these experiments is consistent with the idea that NGF is normally retrogradely transported in association with its receptor. The physiological significance of the retrograde transport of the NGF receptor, or indeed of NGF itself, is not resolved. As previously mentioned, the molecular nature of the signal supplied to the neuronal perikaryon by the NGF:NGF receptor interaction at the distal portion of the neuron is not known. The signal could be NGF itself or some other molecule. The demonstration of the retrograde transport of the receptor raises at least the possibility that the NGF receptor or the NGF:NGF receptor complex is an important molecule conveying the trophic information from the target and might explain why NGF gaining access to the cytoplasm of responsive cells by membrane fusion in culture (thus bypassing the plasma membrane receptor) fails to produce effects in the cells associated with exposure to NGF (Heumann et al., 1981).

One possible role for the retrogradely transported receptor is that it is a means of carrying NGF to the cell body, where NGF, independent of receptor itself, exerts the trophic message. Another possibility is that a second message of unknown molecular nature is generated at the nerve terminal and is subsequently retrogradely transported to cell body to produce trophic effects, while the retrograde transport of NGF and its receptor serves as a mechanism to remove NGF from the terminal and carry it to the cell body for degradation.

It is possible that the NGF receptor is retrogradely transported constitutively (i.e., constantly being anterogradely transported and then retrogradely transported at a fixed rate). Alternatively, the receptor may be retrogradely transported only upon exposure to NGF and subsequent internalization triggered by NGF binding. Distinguishing between these possibilities will require the development of a quantitative assay for the receptor with sufficient sensitivity to measure its accumulation at a ligation site. The receptor could be compared in animals deprived of NGF by anti-NGF and in animals treated with large quantities of NGF. There are, however, indications that internalization and retrograde transport of NGF receptor occur independently of the binding of NGF. The maximum molar quantity of ${ }^{125}$ I192 that can be transported exceeds the amount of NGF likely to be available to binding receptors at the iris (Taniuchi and Johnson, 1985), indicating that receptor molecules can be internalized and retrogradely transported without binding NGF. Injections of ${ }^{125}$ I-NGF into a crush site, at the timc of crush, of axotomized nerve leads to rapid, specific NGF uptake and retrograde transport of radiolabeled protein (Yip and Johnson, 1983; Richardson and Riopelle, 1984), indicating that at least some receptors in retrograde transit are unoccupied; it is likely that these receptors were originally internalized in the unoccupied state.

In summary, these experiments demonstrate that the NGF receptor is anterogradely and retrogradely transported in axons of both the PNS and CNS. This raises the possibility that the NGF receptor has a role in the mechanism of the NGF beyond the initial binding event at the plasma membrane.

\section{References}

Chandler, C. E., L. M. Parsons, M. Hosang, and E. M. Shooter (1984) A monoclonal antibody modulates the interaction of nerve growth factor with PC 12 cells. J. Biol. Chem. 259: 6882-6889.

Chandler, L. P., C. E. Chandler, M. Hosang, and E. M. Shooter (1985) A monoclonal antibody which inhibits epidermal growth factor in different cells. J. Biol. Chem. 260: 3360-3367.

Ebendal, T., L. Olson, and A. Seiger (1983) The level of nerve growth (NGF) as a function of innervation. Exp. Cell Res. 148: 311-317.

Gnahn, H., F. Hefti, R. Heumann, M. E. Schwab, and H. Thoenen (1983) NGF-mediated increase of choline acetyltransferase (ChAT) in the neonatal rat forebrain: Evidence for a physiological role of NGF in the brain? Dev. Brain Res. 9: 45-52.

Hefti, F., A. Dravid, and J. Hartikka (1984) Chronic intraventricular injections of nerve growth factor elevate hippocampal choline acetyltransferase activity in adult rats with partial septohippocampal lesions. Brain Res. 293: 305-311.

Hendry, I. A., K. Stöckel, H. Thoenen, and L. L. Iversen (1974) The retrograde axonal transport of nerve growth factor. Brain Res. 68 : 103-121.

Heumann, R., M. Schwab, and H. Thoenen (1981) A second messenger required for nerve growth factor biological activity? Nature 292: 838-840.

Johnson, E. M., K. M. Rich, and H. K. Yip (1986) The role of NGF in sensory neurons in vivo. Trends Neurosci. 9: 33-37.

Korsching, S., and H. Thoenen (1983a) Nerve growth factor in sympathetic ganglia and corresponding target organs of the rat: Correlation with density of sympathetic innervation. Proc. Natl. Acad. Sci. USA 80: 3513-3516.

Korsching, S., and H. Thoenen (1983b) Quantitative demonstration of retrograde axonal transport of endogenous nerve growth factor. Neurosci. Lett. 39: 1-4.

Korsching, S., G. Auburger, R. Heumann, J. Scott, and H. Thoenen (1985) Levels of nerve growth factor and its mRNA in the central nervous system of the rat correlate with cholinergic innervation. EMBO J. 4: 1389-1393.

Levi-Montalcini, R., and P. Angeletti (1968) Nerve growth factor. Physiol. Rev. 48: 534-569.

Palmatier, M. A., B. K. Hartman, and E. M. Johnson, Jr. (1984) Demonstration of retrogradely transported endogenous nerve growth factor in axons of sympathetic neurons. J. Neurosci. 4: 751-756.

Purves, D. (1976) Functional and structural changes in mammalian sympathetic neurons following colchicine application to post-ganglionic nerves. J. Physiol. (Lond.) 259: 159-175.

Richardson, P. M., and R. J. Riopelle (1984) Uptake of nerve growth factor along peripheral and spinal axons of primary sensory neurons. J. Neurosci. 4: 1683-1689.

Seiler, M., and M. E. Schwab (1984) Specific retrograde transport of nerve growth factor from neocortex to nucleus basalis in the rat. Brain Res. 300: 33-39.

Shelton, D. L., and L. F. Reichardt (1984) Expression of the $\beta$-nerve growth factor gene correlates with the density of sympathetic innervation in effector organs. Proc. Natl. Acad. Sci. USA 81: 7951-7955.

Stöckel, K., M. E. Schwab, and H. Thoenen (1975) Specificity of retrograde transport of nerve growth factor (NGF) in sensory neurons: A biochemical and morphological study. Brain Res. 89: 1-14.

Taniuchi, M., and E. M. Johnson, Jr. (1985) Characterization of the binding properties and retrograde axonal transport of a monoclonal antibody directed against the rat nerve growth factor receptor. J. Cell Biol. 101: 1100-1106.

Taniuchi, M., J. B. Schweitzer, and E. M. Johnson, Jr. (1986a) Nerve growth factor receptor molecules in rat brain. Proc. Natl. Acad. Sci. USA 83: 1950-1954. 
Taniuchi, M., H. B. Clark, and E. M. Johnson, Jr. (1986b) Induction of nerve growth factor receptor in Schwann cells after axotomy. Proc. Natl. Acad. Sci. USA 83: 4094-4098.

Thoenen, H., and Y.-A. Barde (1980) Physiology of nerve growth factor. Physiol. Rev. 60: 1284-1335.
Yip, H. K., and E. M. Johnson, Jr. (1983) Retrograde transport of nerve growth factor in lesioned goldfish retinal ganglion cells. J. Neurosci. 3: $2172-2182$. 